\title{
Comparing post-operative pain between single bundle and double bundle anterior cruciate ligament reconstruction: a retrospective study
}

Chaiwat Chuaychoosakoon*, Wachiraphan Parinyakhup, Arnan Wiwatboworn, Peeranut Purngpiputtrakul, Pawin Wanasitchaiwat and Tanarat Boonriong

\begin{abstract}
Background: In anterior cruciate ligament $(\mathrm{ACL})$ reconstruction, the clinical outcome and level of post-operative pain are important factors. To date there have been no studies evaluating differences in post-operative pain between single bundle and double bundle $A C L$ reconstruction with a hamstring graft.

Hypothesis/purpose: We hypothesized that post-operative pain in single bundle ACL reconstruction would be less than in double bundle ACL reconstruction. This study was to compare post-operative pain between patients undergoing single bundle versus double bundle ACL reconstruction.

Study design: Cohort study.

Methods: This was a retrospective study comparing post-operative pain scores between single bundle and double bundle $A C L$ reconstruction. Each patient was given our standard regimen of oral diclofenac $(25 \mathrm{mg} / \mathrm{tab})$ three times per day and paracetamol (500 mg/tab) six times per day for 1 day post-operatively. If the patient complained of moderate to severe pain (pain numeric rating scale (PNRS) $>3$ ), $3 \mathrm{mg}$ of morphine was injected intravenously every $3 \mathrm{~h}$ for $24 \mathrm{~h}$ and $1 \mathrm{mg}$ of morphine as a rescue medication every $1 \mathrm{~h}$ for $24 \mathrm{~h}$. PNRS and morphine consumption were recorded at 4 - $\mathrm{h}$ intervals for $24 \mathrm{~h}$.

Results: 209 patients were included in this study of whom 102 and 107 patients received single bundle and double bundle ACL reconstruction, respectively. The average post-operative pain scores of the single bundle group were lower at all time points. Linear mixed effect regression analyses showed that the single bungle group had lower post-operative pain than the double bundle group after adjusting for confounders (beta $=-0.45 ; 95 \% \mathrm{Cl}=-$ $0.838,-0.062$ ) but there was no statistically significant difference between numbers of bundle ACL reconstruction with regard to morphine consumption.
\end{abstract}

Conclusion: Single bundle ACL reconstruction had significantly lower post-operative pain scores than double bundle $\mathrm{ACL}$ reconstruction.

\footnotetext{
* Correspondence: psu.chaiwat@gmail.com; chaiwat.c@psu.ac.th Department of Orthopedics, Faculty of Medicine, Prince of Songkla University, 15 Karnjanavanich Road, Hat Yai, Songkhla 90110, Thailand
}

(c) The Author(s). 2021 Open Access This article is licensed under a Creative Commons Attribution 4.0 International License, which permits use, sharing, adaptation, distribution and reproduction in any medium or format, as long as you give appropriate credit to the original author(s) and the source, provide a link to the Creative Commons licence, and indicate if changes were made. The images or other third party material in this article are included in the article's Creative Commons licence, unless indicated otherwise in a credit line to the material. If material is not included in the article's Creative Commons licence and your intended use is not permitted by statutory regulation or exceeds the permitted use, you will need to obtain permission directly from the copyright holder. To view a copy of this licence, visit http://creativecommons.org/licenses/by/4.0/ The Creative Commons Public Domain Dedication waiver (http://creativecommons.org/publicdomain/zero/1.0/) applies to the data made available in this article, unless otherwise stated in a credit line to the data. 
Clinical relevance: Double bundle $A C L$ reconstruction results in higher post-operative pain, which may slow the start of rehabilitation and reduce patient satisfaction. In middle-aged adult patients with low-demand activities, we suggest performing a single bundle $\mathrm{ACL}$ reconstruction.

Keywords: Anterior cruciate ligament, Arthroscopic surgery, Post-operative pain, Reconstruction

\section{Introduction}

The reported pain levels following arthroscopic anterior cruciate ligament (ACL) surgery depend on various factors such as pre-operative pain toleration [1-4], associated intraarticular knee pathologies and operative procedure $[2,5]$, but regardless of the particulars, such pain is an obstacle to beginning early post-operative rehabilitation and also affects the satisfaction of the patient concerning their operation.

In ACL reconstruction, there are two widely used autograft types, bone-patellar-tendon-bone (BPTB) and semitendinosus-gracilis (STG). Gupta et al. compared the degree of post-operative pain between the BPTB and STG methods in single bundle reconstruction and found that post-operative pain was higher in the BPTB group [6]. As well as discussing the graft choice with the patient in ACL reconstruction, the number of bundles used is also an issue. Normally, either single bundle or double bundle grafts can be used in ACL reconstruction. There are many studies comparing the clinical and functional outcomes (Lysholm scores, Tegner scores, subjective International Knee Documentation Committee (IKDC) between single bundle and double bundle grafts in ACL reconstruction which have reported no significant differences between the two groups [7-9]. Because of these results, differences in the level of post-operative pain between the two methods becomes an important factor in making the decision about which type of ACL reconstruction the patient wishes.

There has one been only one study comparing postoperative pain between the two methods, which reported that double ACL reconstruction resulted in higher postoperative pain than single bundle reconstruction [10]; however, this was a preliminary report presented at a conference via abstract without full details, which have to date not been published. The purpose of this study was to compare post-operative pain between patients undergoing single bundle versus double bundle ACL reconstruction. We hypothesized that post-operative pain in single bundle ACL reconstruction would be less than in double bundle ACL reconstruction.

\section{Materials and methods}

This study was a retrospective chart review of 271 records of patients aged between 18 and 50 years old who had received arthroscopic ACL reconstruction from January 2016 to December 2019, of which 62 records were excluded. (Fig. 1). Patients who had undergone a revision ACL reconstruction or who had a history of intraarticular knee fracture or previous knee surgery and associated injuries involving the posterior cruciate ligament or medial/lateral collateral ligament were excluded (Fig. 1). The study was approved by the Ethics Committee of the Faculty of Medicine of Prince of Songkla University, which also agreed to waive informed consent. All procedures were carried out in accordance with relevant guidelines and regulations.

Demographic data such as age, gender, body mass index (BMI), side of operation, concomitant intraarticular injuries (meniscal injury and/or cartilage injury), concomitant surgery (meniscal repair), post-operative pain scores and volume of morphine use were recorded with a standard recording form. The choice of single bundle or double bundle ACL reconstruction was made depending on the physician preference. Single bundle ACL reconstruction was performed by T.B., while double bundle ACL reconstruction was performed by W.P.. All patients were followed for 1 day after their surgery to assess their post-operative pain and amount of morphine consumption. Post-operative pain scores and volume of morphine consumption were recorded every $4 \mathrm{~h}$ for the first day after the surgery. The post-operative pain was assessed using an 11-point pain numeric rating scale (PNRS), with 0 representing no pain and 10 the worst pain imaginable.

\section{Surgical procedures}

The single bundle ACL reconstructions were performed by a single experienced sports medicine orthopedist (T.B.). Briefly, in each procedure, the patient was placed in the supine position with a thigh tourniquet. An oblique incision was made over the pes anserinus. The semitendinosus and gracilis tendons were harvested and a six-strand bundle prepared for the reconstruction. An anterolateral viewing portal was created, and anteromedial and accessory anteromedial portals for instrumentation. An arthroscopic examination was first done to evaluate the intraarticular pathology. Then, the centers of the femoral and tibial footprints were used as landmarks to create femoral and tibial tunnels, the size depending on the graft size.

The double bundle ACL reconstructions were done by another experienced sports medicine orthopedist (W.P.). The procedures of graft harvesting and portal creation 


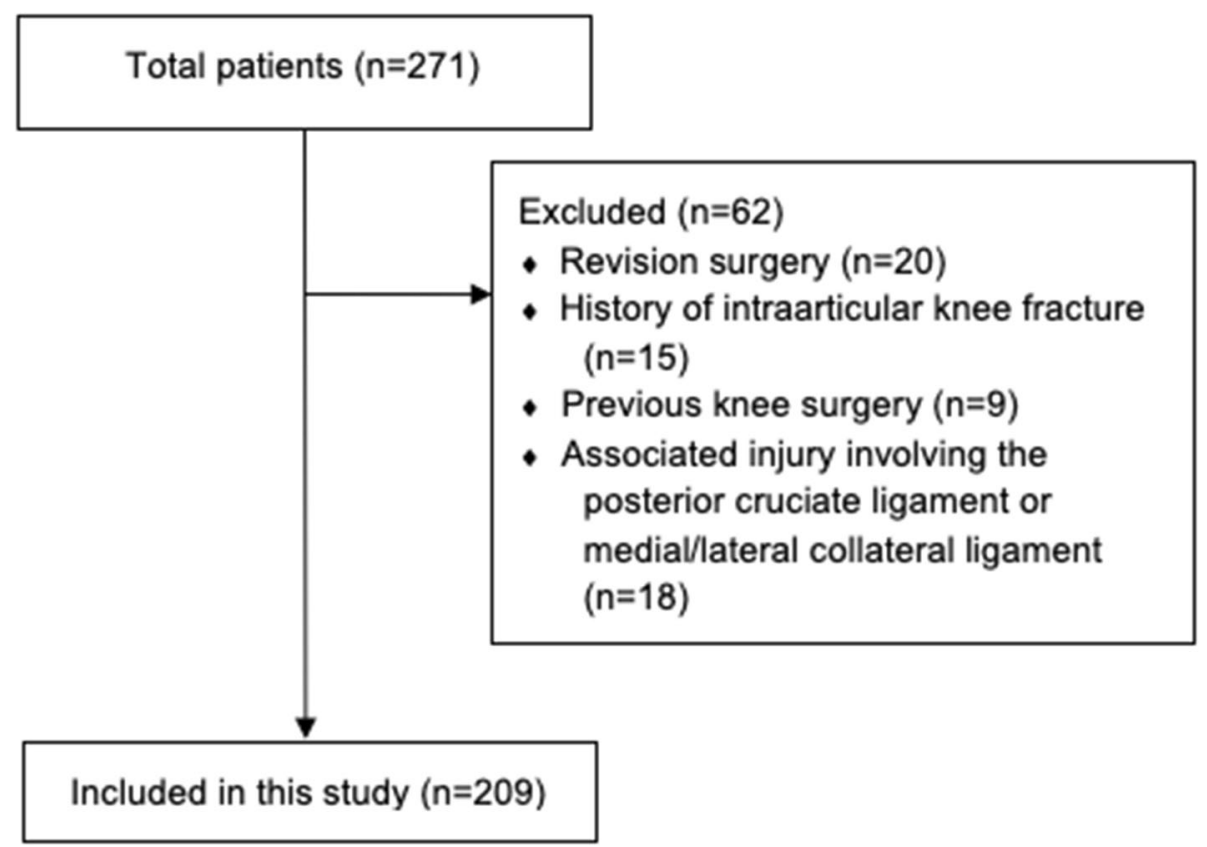

Fig. 1 Enrollment flowchart

were the same as in the single bundle reconstruction. A 3 -strand bundle was prepared from the semitendinosus tendon for the AM bundle and a 3-strand bundle was prepared from the gracilis tendon for the PL bundle. Anteromedial and posterolateral femoral tunnels and two tibial tunnels were created based on the anatomical footprint of the AM and PL bundles.

In all procedures, an EndoButton (Smith \& Nephew Endoscopy, Andover, MA) was used for femoral fixation and a Biosure HA (Smith \& Nephew Endoscopy, Andover, MA) for tibial fixation.

\section{Analgesic protocols Intraoperative analgesia}

Before the first incision, the patient was anesthetized by an experienced anesthesiologist with a combination spinal nerve block of $3.5 \%$ heavy Marcaine with an adductor nerve block using 0.25\% Marcaine. The level of the analgesic block was at least L2.

\section{Post-operative analgesia}

Following the operation, each patient was given oral analgesia of diclofenac $(25 \mathrm{mg} / \mathrm{tab})$ three times a day and paracetamol $(500 \mathrm{mg} / \mathrm{tab})$ six times per day for 1 day. Both reconstruction groups underwent the same early rehabilitation protocol. All patients were fitted with a locked long knee brace in full extension. Isometric quadriceps exercises and active straight leg raising were started on post-operative day 1 . If a patient complained of moderate or severe pain (PNRS > 3), $3 \mathrm{mg}$ of morphine would be given intravenously every $3 \mathrm{~h}$ for 24 $\mathrm{h}$ and $1 \mathrm{mg}$ of morphine as a rescue analgesic every $1 \mathrm{~h}$.

\section{Statistical analysis}

Continuous data such as post-operative pain scores, $\mathrm{cu}$ mulative doses of morphine, operative time, and tourniquet time were analyzed using mean \pm standard deviation and the paired t-test and ANOVA. Categorical data such as gender, concomitant intraarticular injuries (cartilage injury, meniscal injury), concomitant surgery (meniscal repair) were analyzed with the chi-squared test. We used multivariate linear mix effect regression to assess difference in post-operative pain score between single bundle and double bundle reconstruction techniques with adjustment for confounding by postoperative time, age, sex, concomitant surgery (meniscal repair), and concomitant intraarticular injuries (meniscal or cartilage injuries). A $p$-value of 0.05 was considered significant. Statistical analyses were done using the $R$ program and epicalc package (version 3.4.3; R Foundation for Statistical Computing, Vienna, Austria).

\section{Results}

\section{Participants}

The study included 209 patients, 187 males and 22 females. Single bundle or double bundle ACL reconstructions were performed on 102 and 107 patients, respectively. The demographic data are shown in Table 1 , with no statistically significant differences in baseline characteristics between the single bundle and double 
Table 1 Patient characteristics comparing the single bundle reconstruction and double bundle reconstruction groups

\begin{tabular}{|c|c|c|c|}
\hline Characteristic & Single bundle (102) & Double bundle (107) & $p$-value \\
\hline Age (SD) & $33.0(10.5)$ & $29.8(8.3)$ & 0.015 \\
\hline Body mass index (SD) & $24.2(3.5)$ & $24.6(4.5)$ & 0.381 \\
\hline Side & & & 0.113 \\
\hline - Right & $46(45.1)$ & $61(57.0)$ & \\
\hline - Left & $56(54.9)$ & $46(43.0)$ & \\
\hline Level of spinal block & & & 0.841 \\
\hline$\cdot \mathrm{T} 10-12$ & $64(64.0)$ & $66(61.7)$ & \\
\hline$\cdot L 1-L 2$ & $36(36.0)$ & $41(38.3)$ & \\
\hline Tourniquet time (minutes) & $85.0(39.5)$ & $100.0(27.0)$ & $<0.001$ \\
\hline Concomitant intraarticular injuries & & & $>0.05$ \\
\hline - Medial meniscal injury & $58(56.9)$ & $65(60.7)$ & \\
\hline - Lateral meniscal injury & $47(46.1)$ & $46(43.0)$ & \\
\hline - Cartilage injury & $12(11.8)$ & $11(10.3)$ & \\
\hline Concomitant surgery & & & $>0.05$ \\
\hline - Medial meniscal repair & $31(30.4)$ & $42(39.2)$ & \\
\hline - 1 suture & $10(9.8)$ & $12(11.2)$ & \\
\hline$\circ 2$ sutures & $15(14.7)$ & $18(16.8)$ & \\
\hline$\circ 3$ sutures & $5(4.9)$ & $8(7.5)$ & \\
\hline$\circ 4$ sutures & $1(1.0)$ & $4(3.7)$ & \\
\hline - Lateral meniscal repair & $17(16.7)$ & $22(20.6)$ & \\
\hline ○ 1 suture & $5(4.9)$ & $7(6.5)$ & \\
\hline$\circ 2$ sutures & $9(8.8)$ & $12(11.2)$ & \\
\hline$\circ 3$ sutures & $2(2.0)$ & $2(1.9)$ & \\
\hline$\circ 4$ sutures & $1(1.0)$ & $1(1.0)$ & \\
\hline
\end{tabular}

Single bundle reconstruction versus Double bundle reconstruction: PNRS.

bundle reconstruction groups except average age and tourniquet time.

The average post-operative pain scores (Fig. 2) were lower in the single bundle group than in the double bundle group at all post-operative time points. Linear mixed effect regression analyses (Table 2) showed that the average post-operative pain score in the single bundle group was 0.45 points lower than the score in the double bundle group (beta $=-0.45 ; 95 \% \mathrm{CI}=-0.838,-0.062$ ). The model also showed that for every one-year increased in age, the post-operative pain score decreased by an average of 0.04 point (beta $=-0.04,95 \% \mathrm{CI}=-0.060$, $0.020)$.

The cumulative doses of morphine consumed during the post-operative period in the single bundle and double bundle groups are shown in Fig. 3. There were no statistically significant differences between two groups at all time points ( $p$-value $\geq 0.05)$.

\section{Discussion}

The single bundle ACL reconstruction group had consistently lower post-operative pain scores than the double bundle ACL reconstruction group, but the cumulative doses of morphine were not different between the two groups.

In recent years, many studies have compared the outcomes between single bundle and double bundle grafts in ACL reconstruction, and overall found no significant differences in clinical and functional outcomes (Lysholm scores [11-20], Tegner scores [12, $14,17,19,21]$, subjective IKDC $[8,12,16,17,19$, 22-24]), although some studies reported that the double bundle ACL reconstruction gave better rotational stability as assessed by the pivot shift test [16, $22,25]$ and objective IKDC $[16,21,26]$. The disadvantages of the double bundle $\mathrm{ACL}$ reconstruction are that it is technically demanding, has a longer operation time, and it is more difficult to do revision surgery in case of a re-ruptured ACL [27]. Due to the comparatively equal clinical outcomes between single and double bundle ACL reconstructions, differences in the level of post-operative pain between the two methods becomes an important factor in making the decision about which technique to use. Additionally, post-operative pain is one of the most important factors that affect the rehabilitation program and the 


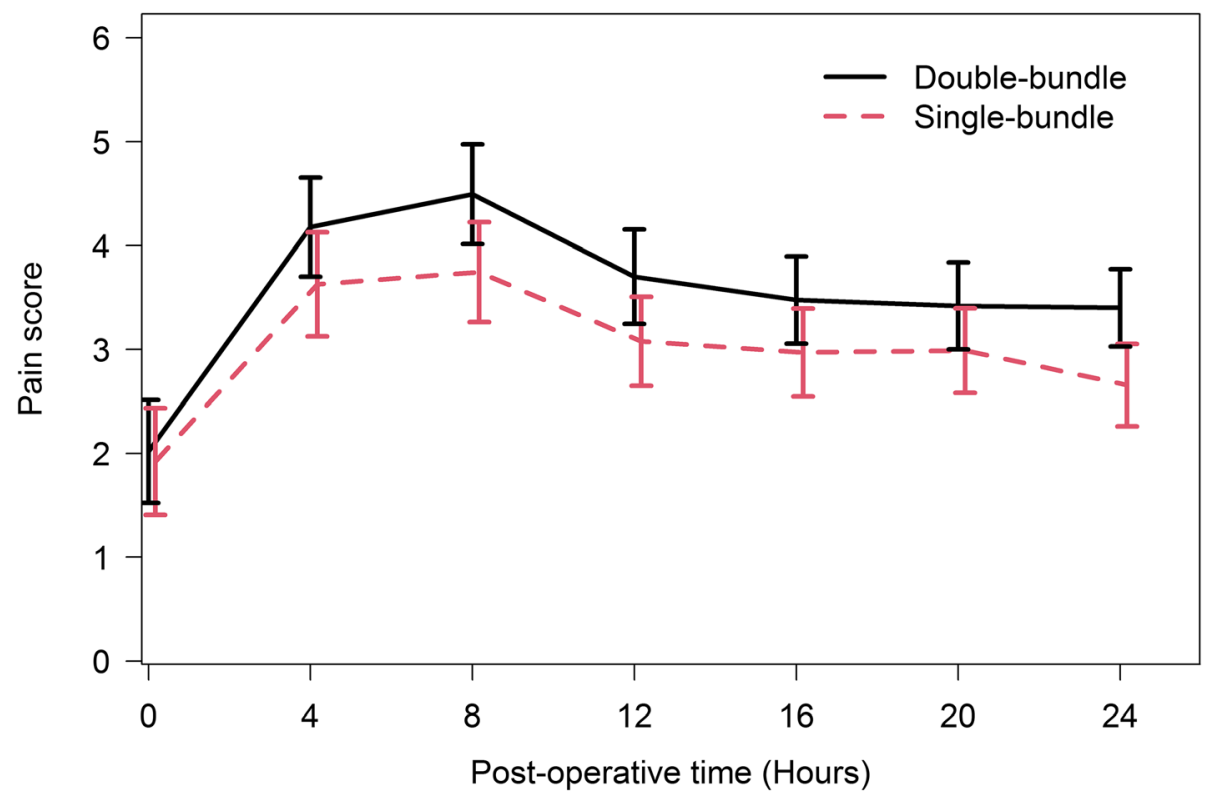

Fig. 2 Comparing average post-operative pain scores between the single bundle and double bundle ACL reconstruction groups during the first $24 \mathrm{~h}$ after surgery

patient's satisfaction [6, 28, 29]. Moderate to severe post-operative pain can delay the start of the rehabilitation program thus increasing the chance of a poor functional outcome $[6,28]$.
A literature review found only one preliminary study comparing post-operative pain between single bundle and double bundle reconstruction, which reported that the double bundle group had higher post-operative pain

Table 2 Parameters of the generalized linear model on the association between singe bundle and double bundle ACL reconstruction groups and post-operative pain with potential confounders ( $N=209$ patients) (* Statistically significant, $p$-value < 0.05 )

\begin{tabular}{|c|c|c|c|c|c|}
\hline Variable & $\begin{array}{l}\text { Regression Coefficient } \\
\text { (beta) }\end{array}$ & $\begin{array}{l}\text { Standard } \\
\text { Error }\end{array}$ & $\begin{array}{l}95 \% \mathrm{Cl} \\
\text { (Lower) }\end{array}$ & $\begin{array}{l}95 \% \mathrm{Cl} \\
\text { (Upper) }\end{array}$ & $\begin{array}{l}P \text { - } \\
\text { value }\end{array}$ \\
\hline $\begin{array}{l}\text { Numbers of bundle ACL Reconstruction: double bundle (Ref. } \\
\text { single bundle) }\end{array}$ & -0.45 & 0.198 & -0.838 & -0.062 & $0.0228^{*}$ \\
\hline \multicolumn{6}{|l|}{ Post-operative time (Ref. 0 h) } \\
\hline $4 \mathrm{~h}$ & 1.94 & 0.193 & 1.562 & 2.318 & $\begin{array}{l}< \\
0.001^{*}\end{array}$ \\
\hline $8 \mathrm{~h}$ & 2.16 & 0.193 & 1.782 & 2.538 & $\begin{array}{l}< \\
0.001^{*}\end{array}$ \\
\hline $12 \mathrm{~h}$ & 1.43 & 0.193 & 1.052 & 1.808 & $\begin{array}{l}< \\
0.001^{*}\end{array}$ \\
\hline $16 \mathrm{~h}$ & 1.26 & 0.193 & 0.882 & 1.638 & $<.001^{*}$ \\
\hline $20 \mathrm{~h}$ & 1.24 & 0.193 & 0.862 & 1.618 & $\begin{array}{l}< \\
0.001^{*}\end{array}$ \\
\hline $24 \mathrm{~h}$ & 1.07 & 0.193 & 0.692 & 1.448 & $<.001^{*}$ \\
\hline Age in years (continuous) & -0.04 & 0.010 & -0.060 & -0.020 & $<.001^{*}$ \\
\hline Sex: Female (Ref. Male) & 0.52 & 0.317 & -0.101 & 1.141 & 0.106 \\
\hline Concomitant intraarticular injuries (Ref. no injury) & 0.04 & 0.274 & -0.497 & 0.577 & 0.885 \\
\hline Meniscal repair (Ref. no repair) & -0.16 & 0.227 & -0.605 & 0.285 & 0.487 \\
\hline
\end{tabular}

Single bundle reconstruction versus Double bundle reconstruction: Morphine consumption. 


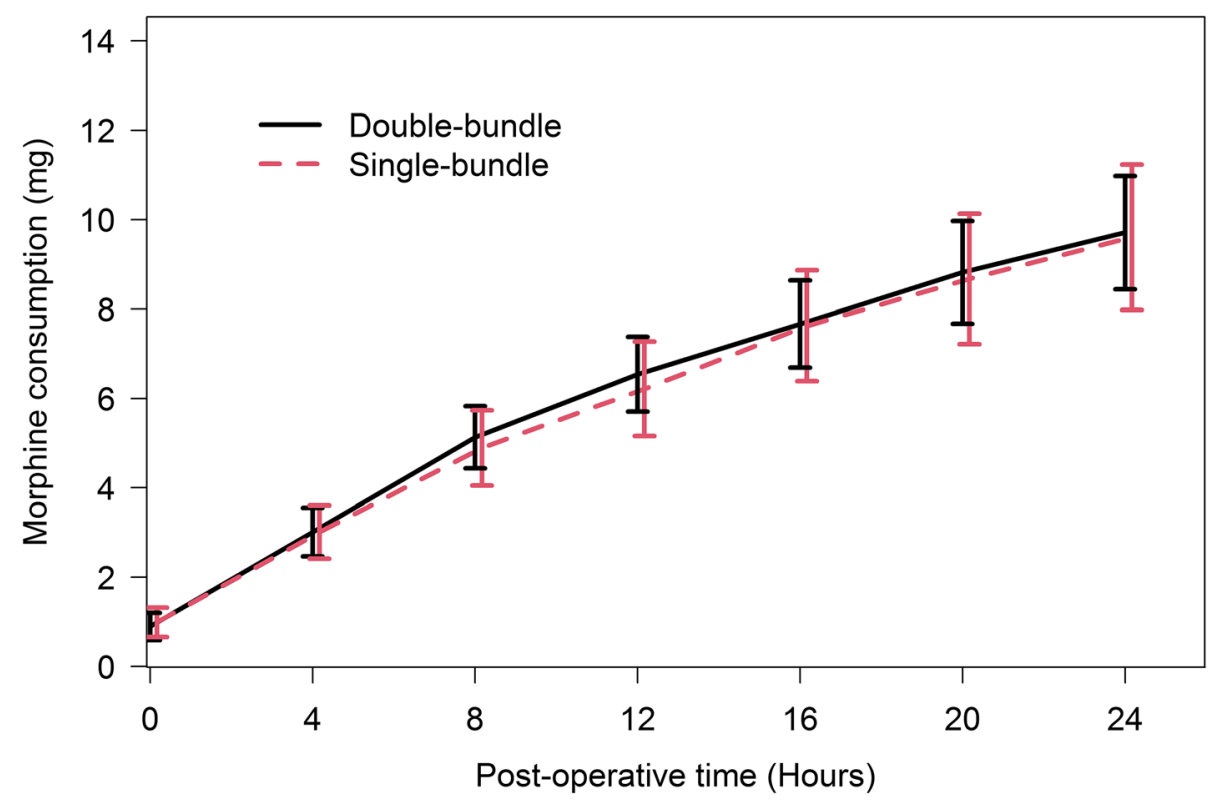

Fig. 3 Comparing average cumulative doses of morphine between the single bundle ACL reconstruction and double bundle ACL reconstruction groups during the first $24 \mathrm{~h}$ after surgery

than the single bundle group [10], similar to our study. Our study found the average post-operative pain scores in the single bundle group were lower than in the double bundle group at all post-operative time points, furthermore linear mixed effect regression analyses showed that the average post-operative pain score was affected by numbers of bundle ACL reconstruction and age. Higher post-operative pain following double bundle reconstruction is probably related to the number and size of the bone tunnels used between the two techniques. Single bundle reconstruction uses one large bone tunnel in both the femur and tibia while double bundle reconstruction uses two small bone tunnels in both bones. While age related post-operative pain in this study was similar to the systematic review of Lautenbacher et al. [30] which reported that middle-aged adult patients had lower pain sensitivity than young adult patients because of higher pain thresholds. In clinical application, we suggest the surgeon should perform a single bundle ACL reconstruction in middle-aged adult patients rather than the double bundle ACL reconstruction because of the levels of post-operative pain scores and generally lower levels of demanding activities in this patient group. In contrast, the surgeon can do a double bundle ACL reconstruction in young adult patients, but the surgeon should be prepared for more intense post-operative pain control.

There were several limitations to this study. First, there are many factors that can affect post-operative pain such as pain toleration, anxiety and psychological stress that were not evaluated in this study. Second, this study was a retrospective study thus there was a risk of selection bias; however, we evaluated the risk of selection bias by analyzing the baseline characteristics of the patients and confirmed there were no statistically significant differences between the single and double bundle reconstruction groups except age and tourniquet time. However, we used multivariate linear mix effect regression to assess difference in post-operative pain score between single bundle and double bundle reconstruction techniques with adjustment for confounding to determine the results. Third, the PNRSs are recorded by the on-duty orthopedic nurses, and we did not attempt to ensure they had all done these assessments in a consistent way; however, the potential for bias was low because post-operative assessments are done following a standard protocol. Fourth, each surgical technique was done by a different orthopaedist, which could have influenced the results by a chance of selection bias. However, we minimized this bias by analyzed the results with regression model. Additionally, both surgeons are well experienced in both procedures which minimizes the learning curve of each procedure; T.B. is more highly experienced in single bundle ACL reconstruction and performed all of these procedures, while W.P. is more highly experienced in double bundle ACL reconstructions and performed all of these procedures.

\section{Conclusion}

Single bundle ACL reconstruction had significantly lower post-operative pain scores than double bundle ACL reconstruction, but the cumulative doses of 
morphine consumption were not different between the two groups.

\section{Abbreviations}

ACL: Anterior cruciate ligament, BMI: Body mass index; BMI: Body mass index; BPTB: Bone-patellar-tendon-bone, IKDC: International Knee Documentation Committee; IKDC: International Knee Documentation Committee;

STG: Semitendinosus-gracilis; PNRS: Pain numeric rating scale

\section{Acknowledgements}

The authors sincerely thank Boonsin Tangtrakulwanich of the Orthopedics Department; Wit Wichaidit and Nannapat Pruphetkaew of the Epidemiology Unit, Faculty of Medicine for providing statistical support; and David Patterson of the Office of International Affairs of the Faculty of Medicine for his editing assistance.

\section{Guidelines statement}

STROBE statement.

\section{Conflict of interests}

Each author certifies that he or she has no commercial associations that might pose a conflict of interest in connection with the submitted article.

\section{Authors' contributions}

C.C., T.B. and W.P. conceived of the study idea. C.C., A.W., P.P. and P.W. developed the theory and collected the data. C.C. verified the analytical methods. All authors discussed the results and contributed to the final manuscript. The author(s) read and approved the final manuscript.

\section{Funding}

None.

\section{Availability of data and materials}

The datasets used and/or analysed during the current study are available from the corresponding author on reasonable request.

\section{Declarations}

\section{Ethics approval and consent to participate}

I can inform you that the Ethics Committee of Prince of Songkla University approved this study protocol (REC 63-175-11-1) before the study was undertaken. Each author certifies that the ethical committee of Prince of Songkla University has already approved this study protocol (REC 63-175-111).

\section{Consent for publication}

NA

\section{Competing interests}

None.

Received: 25 May 2021 Accepted: 16 August 2021

Published online: 03 September 2021

\section{References}

1. Bisgaard T, Klarskov B, Rosenberg J, Kehlet H. Characteristics and prediction of early pain after laparoscopic cholecystectomy. Pain. 2001;90(3):261-9. https://doi.org/10.1016/s0304-3959(00)00406-1.

2. Kalkman CJ, Visser K, Moen J, Bonsel GJ, Grobbee DE, Moons KGM. Preoperative prediction of severe postoperative pain. Pain. 2003;105(3):41523. https://doi.org/10.1016/s0304-3959(03)00252-5.

3. Mamie C, Bernstein M, Morabia A, Klopfenstein CE, Sloutskis D, Forster A. Are there reliable predictors of postoperative pain? Acta Anaesthesiol Scand. 2004;48(2):234-42. https://doi.org/10.1111/j.0001-5172.2004.00298.x.

4. Rudin A, Wölner-Hanssen P, Hellbom M, Werner MU. Prediction of postoperative pain after a laparoscopic tubal ligation procedure. Acta Anaesthesiol Scand. 2008;52(7):938-45. https://doi.org/10.1111/j.1399-6576.2 008.01641.X.

5. Chung F, Ritchie E, Su J. Postoperative pain in ambulatory surgery. Anesth Analg. 1997;85(4):808-16. https://doi.org/10.1097/00000539-199710000-0001 7.
6. Gupta R, Kapoor D, Kapoor L, Malhotra A, Masih GD, Kapoor A, et al. Immediate post-operative pain in anterior cruciate ligament reconstruction surgery with bone patellar tendon bone graft versus hamstring graft. J Orthop Surg Res. 2016;11(1):1-6. https://doi.org/10.1186/s13018-016-0399-5.

7. Dong Z, Niu Y, Qi J, Song Y, Wang F. Long term results after double and single bundle ACL reconstruction: is there any difference? A meta - analysis of randomized controlled trials. Acta Orthop Traumatol Turc. 2019;53(2):929. https://doi.org/10.1016/j.aott.2018.12.004.

8. Mayr HO, Benecke P, Hoell A, Schmitt-Sody M, Bernstein A, Suedkamp NP, et al. Single-bundle versus double-bundle anterior cruciate ligament reconstruction: a comparative 2-year follow-up. Arthroscopy. 2016;32(1):3442. https://doi.org/10.1016/j.arthro.2015.06.029.

9. Tiamklang T, Sumanont S, Foocharoen T, Laopaiboon M. Double-bundle versus single-bundle reconstruction for anterior cruciate ligament rupture in adults. Cochrane Database Syst Rev. 2012;11(11):CD008413. https://doi.org/1 0.1002/14651858.CD008413.pub2.

10. Heard M, Hiemstra LA, Sasyniuk TM, Monteleone BJ. A prospective comparison of postoperative pain and medication use between single and double bundle anterior cruciate ligament (ACL) reconstruction (SS-45). Arthrosc J Arthrosc Relat Surg. 2009;25(6):e24-5. https://doi.org/10.1016/j.a rthro.2009.04.044.

11. Fujita N, Kuroda R, Matsumoto T, Yamaguchi M, Yagi M, Matsumoto A, et al. Comparison of the clinical outcome of double-bundle, anteromedial singlebundle, and posterolateral single-bundle anterior cruciate ligament reconstruction using hamstring tendon graft with minimum 2-year followup. Arthroscopy. 2011;27(7):906-13. https://doi.org/10.1016/j.arthro.2011.02. 015.

12. Gobbi A, Mahajan V, Karnatzikos G, Nakamura N. Single- versus doublebundle $A C L$ reconstruction: is there any difference in stability and function at 3-year followup? Clin Orthop Relat Res. 2012;470(3):824-34. https://doi. org/10.1007/s11999-011-1940-9.

13. Koga H, Muneta T, Yagishita K, Watanabe T, Mochizuki T, Horie M, et al. Midto long-term results of single-bundle versus double-bundle anterior cruciate ligament reconstruction: randomized controlled trial. Arthroscopy. 2015; 31(1):69-76. https://doi.org/10.1016/j.arthro.2014.07.020.

14. Lee S, Kim H, Jang J, Seong SC, Lee MC. Comparison of anterior and rotatory laxity using navigation between single- and double-bundle ACL reconstruction: prospective randomized trial. Knee Surg Sports Traumatol Arthrosc. 2012;20(4):752-61. https://doi.org/10.1007/s00167-012-1880-2.

15. Ochiai S, Hagino T, Senga S, Saito M, Haro H. Prospective evaluation of patients with anterior cruciate ligament reconstruction using a patientbased health-related survey: comparison of single-bundle and anatomical double-bundle techniques. Arch Orthop Trauma Surg. 2012;132(3):393-8. https://doi.org/10.1007/s00402-011-1443-x.

16. Siebold R, Dehler C, Ellert T. Prospective randomized comparison of doublebundle versus single-bundle anterior cruciate ligament reconstruction. Arthroscopy. 2008;24(2):137-45. https://doi.org/10.1016/j.arthro.2007.11.013.

17. Streich NA, Friedrich K, Gotterbarm T, Schmitt H. Reconstruction of the ACL with a semitendinosus tendon graft: a prospective randomized single blinded comparison of double-bundle versus single-bundle technique in male athletes. Knee Surg Sports Traumatol Arthrosc. 2008;16(3):232-8. https://doi.org/10.1007/s00167-007-0480-z.

18. Suomalainen P, Jarvela T, Paakkala A, Kannus P, Jarvinen M. Double-bundle versus single-bundle anterior cruciate ligament reconstruction: a prospective randomized study with 5-year results. Am J Sports Med. 2012; 40(7):1511-8. https://doi.org/10.1177/0363546512448177.

19. Wang J-Q, Ao Y-F, Yu C-L, Liu P, Xu Y, Chen L-X. Clinical evaluation of double-bundle anterior cruciate ligament reconstruction procedure using hamstring tendon grafts: a prospective, randomized and controlled study. Chin Med J. 2009;122(6):706-11.

20. Zhang Z, Gu B, Zhu W, Zhu L. Double-bundle versus single-bundle anterior cruciate ligament reconstructions: a prospective, randomized study with 2year follow-up. Eur J Orthop Surg Traumatol. 2014;24(4):559-65. https://doi. org/10.1007/s00590-013-1221-2.

21. Zaffagnini S, Bruni D, Russo A, Takazawa Y, Lo Presti M, Giordano G, et al. ST/G ACL reconstruction: double strand plus extra-articular sling vs double bundle, randomized study at 3-year follow-up. Scand J Med Sci Sports. 2008;18(5):573-81. https://doi.org/10.1111/j.1600-0838.2007.00697.x.

22. Hussein M, van Eck CF, Cretnik A, Dinevski D, Fu FH. Prospective randomized clinical evaluation of conventional single-bundle, anatomic single-bundle, and anatomic double-bundle anterior cruciate ligament 
reconstruction: 281 cases with 3- to 5-year follow-up. Am J Sports Med. 2012;40(3):512-20. https://doi.org/10.1177/0363546511426416.

23. Nunez M, Sastre S, Nunez E, Lozano L, Nicodemo C, Segur JM. Healthrelated quality of life and direct costs in patients with anterior cruciate ligament injury: single-bundle versus double-bundle reconstruction in a low-demand cohort--a randomized trial with 2 years of follow-up. Arthroscopy. 2012;28(7):929-35. https://doi.org/10.1016/j.arthro.2011.11.034.

24. Xu Y, Ao Y, Wang J, Cui G. Prospective randomized comparison of anatomic single- and double-bundle anterior cruciate ligament reconstruction. Knee Surg Sports Traumatol Arthrosc. 2014;22(2):308-16. https://doi.org/10.1007/ s00167-013-2398-y.

25. Ibrahim SAR, Hamido F, Al Misfer AK, Mahgoob A, Ghafar SA, Alhran H. Anterior cruciate ligament reconstruction using autologous hamstring double bundle graft compared with single bundle procedures. J Bone Joint Surg Br. 2009:91(10):1310-5. https://doi.org/10.1302/0301-620X.91B10.21886.

26. Volpi P, Cervellin M, Denti M, Bait C, Melegati G, Quaglia A, et al. ACL reconstruction in sports active people: transtibial DB technique with ST/G vs. transtibial SB technique with BPTB: preliminary results. Injury. 2010;41 (11): 1168-71. https://doi.org/10.1016/j.injury.2010.09.029.

27. Prodromos CC, Fu FH, Howell SM, Johnson DH, Lawhorn K. Controversies in soft-tissue anterior cruciate ligament reconstruction: grafts, bundles, tunnels, fixation, and harvest. J Am Acad Orthop Surg. 2008;16(7):376-84. https://doi. org/10.5435/00124635-200807000-00003.

28. Gan TJ. Poorly controlled postoperative pain: prevalence, consequences, and prevention. J Pain Res. 2017;10:2287-98. https://doi.org/10.2147/JPR. S144066.

29. Wu CL, Raja SN. Treatment of acute postoperative pain. Lancet. 2011; 377(9784):2215-25. https://doi.org/10.1016/S0140-6736(11)60245-6.

30. Lautenbacher S, Peters JH, Heesen M, Scheel J, Kunz M. Age changes in pain perception: a systematic-review and meta-analysis of age effects on pain and tolerance thresholds. Neurosci Biobehav Rev. 2017;75:104-13. https://doi.org/10.1016/..neubiorev.2017.01.039

\section{Publisher's Note}

Springer Nature remains neutral with regard to jurisdictional claims in published maps and institutional affiliations.

Ready to submit your research? Choose BMC and benefit from:

- fast, convenient online submission

- thorough peer review by experienced researchers in your field

- rapid publication on acceptance

- support for research data, including large and complex data types

- gold Open Access which fosters wider collaboration and increased citations

- maximum visibility for your research: over $100 \mathrm{M}$ website views per year

At $\mathrm{BMC}$, research is always in progress.

Learn more biomedcentral.com/submissions 